\title{
Summary of phylogeny in subfamily Colobinae (Primate: Cercopithecidae)
}

\author{
WANG XiaoPing ${ }^{1}$, ZHANG YaPing ${ }^{1,3} \& \mathrm{YU} \mathrm{Li}^{1,2^{*}}$ \\ ${ }^{1}$ Laboratory for Conservation and Utilization of Bio-resource, Yunnan University, Kunming 650091, China; \\ ${ }^{2}$ Key Laboratory for Animal Genetic Diversity and Evolution of High Education in Yunnan Province, Yunnan University, Kunming 650091, \\ China; \\ ${ }^{3}$ State Key Laboratory of Genetic Resources and Evolution, Kunming Institute of Zoology, Chinese Academy of Sciences, Kunming 650223, China
}

Received March 12, 2012; accepted May 25, 2012; published online January 9, 2013

The phylogeny of the colobine monkeys has a complex evolutionary history, evolving several distinct radiations and owned a wide range of forest and woodland habits in tropical Africa and in southern and eastern Asia. Understanding the true evolutionary history of the colobine monkeys becomes an important field and has received special attention. In this article, we review phylogeny of Colobinae based on previous fossil, cytological, morphological and molecular evidence and indicate the phylogenetic controversies. This review is expected to guide the future research of Colobinae phylogeny, and also provide theoretic evidence for the conservation of these highly endangered and unique primates.

Colobinae, phylogeny, Asian presbytina, African colobinae

Citation: Wang X P, Zhang Y P, Yu L. Summary of phylogeny in subfamily Colobinae (Primate: Cercopithecidae). Chin Sci Bull, 2013, 58: 2097-2103, doi: $10.1007 /$ s11434-012-5624-y

The Old World monkeys consist of two living subfamilies - the cheek-pouch monkeys (Cercopithecinae) and the leafeating monkeys (Colobinae) [1], both of which are the closest living relatives to the apes (Hominoidea) (Figure 1) [1], but previous studies had focused on Cercopithecine evolution as a model for human evolution history. The phylogenetic and evolution of the leaf-eating monkeys (Colo-

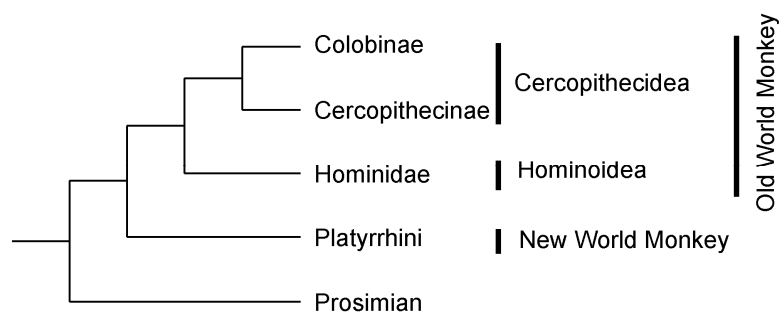

Figure 1 The phylogeny of main families in primates.

\footnotetext{
*Corresponding author (email: yuli1220@yahoo.com.cn)
}

binae), on the other hand, had been a relatively neglected issue. In these years, the colobine monkeys, especially Asian colobines, are facing extinction because of the increasing deforestation and hunting rates by people. Therefore, it is necessary for us to promote the conservation of these highly endangered and unique primates.

Compared with Cercopithecinae, the colobine monkeys have a sharp-cusped cheek teeth and relatively narrow incisors [2]. Their dimensions vary from $4 \mathrm{~kg}$ in the African olive colobus (Procolobus verus) to $20 \mathrm{~kg}$ of the adult males of the proboscis monkey in Borneo (Nasalis larvatus). They are characterized by the very short and in some case degraded thumb. The hind legs are usually longer than the front legs. Most of the species have no cheek pouch outside, and have very long tail except the pig-tailed langur (Simias concolor) [3].

Besides the features as described above, the subfamily Colobinae has evolved a complex ruminant-like stomach and foregut in which microbes ferment these indigestible plant materials [4], leading to their unique adaptation to the 
leaf-eating feeding habits [5-8]. In view of this, the Colobinae has also been the crucial model animals for the study of the molecular mechanisms of adaptive evolution $[9,10]$. The pancreatic ribonuclease gene (RNASE) duplication has been believed to be closely related to the adaptation of Colobines to the unique leaf-feeding lifestyle [5-8]. While all of the other primates have only one RNASEI gene, multiple RNASEl genes have been intriguingly observed in Colobines, evolving rapidly under positive selection for enhanced digestive efficiencies, as an adaptive response to the increased demands for the enzyme for digesting bacterial RNA (Figure 2).

The colobines consist of 10 genera in two subtribes- the African Colobina (including the genera Colobus, Piliocolobus, and Procolobus) and the Asian Presbytina (including the genera Pygathrix, Rhinopithecus, Nasalis, Simias, Presbytis, Trachypithecus and Semnopithecus) [1,11-14]. Based on fossil records, the divergence between ancestral African colobines and Asian colobines was estimated between 10 [15] and $13 \mathrm{Ma}$ [16]. The colobines not only experience recent and rapid adaptive radiations, but also are more diverse and widespread for different climate environments [12]. In view of this, the phylogeny of the colobine monkeys has a complex evolutionary history, evolving several distinct radiations and owned a wide range of forest and woodland habits in tropical Africa and in southern and eastern Asia. Understanding the true evolutionary history of the colobine monkeys, therefore, becomes an important field and has received special attention. However, due to the fact that nearly all the extant colobine genera diversify from one another within a four-million-year window [17-19], attempts to clarify relationships among these colobine genera have encountered challenges.

In this article, we review the phylogeny of the colobine monkeys based on previous fossil, morphological physiol-

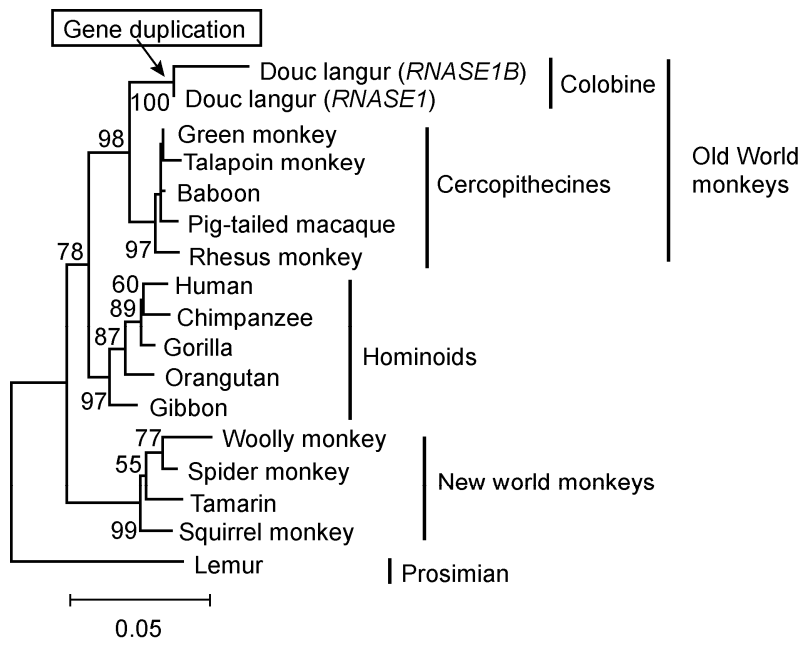

Figure 2 The unique duplication of RNASE1 gene in Colobines compared with other primates [5]. ogy, cytology and molecular evidences, and indicated the phylogenetic controversies. This review is expected to shed light on the research of Colobinae phylogeny and adaptive evolution, and also provide a theoretical foundation for the conservation of these highly endangered and unique primates.

\section{Phylogeny of African Colobinae}

The diversification of African colobines, which distributed across the African rainforest belt, represented a major component of African primate evolution [20,21]. According to fossil records, the earliest African colobines were found in the late Miocene about 8.5-9 Ma [22].

African colobines include three genera, i.e., Colobus (black-and-white colobus), Procolobus (olive colobus), and Piliocolobus (red colobus) [20,23]. Colobus diverged first, and followed by the progenitor of Piliocolobus and Procolobus $[17,19,24-26]$. Based on both morphology and genetics evidence, it was well-recognized that Procolobus was the sister-taxon of (and possibly congeneric to) Piliocolobus $[12,19,24,26-28]$. In other words, there was a general consensus for the more close relationship between Piliocolobus and Procolobus within African colobines.

In earlier analyses of morphological and molecular data, all supported that the African colobine forms a monophyletic clade [1,12,19], grouping Piliocolobus, Procolobus, and Colobus together [17-19,24-26,29,30] (Figure 3). Interestingly, a recent phylogenetic analyses of 83 mobile elements from Roos et al. [19] indicated a closer association of the Procolobus/Piliocolobus clade to Asian colobines than to Colobus, a relationship that was not rejected by nuclear sequence data in their study, leading them to propose African colobines paraphyly hypothesis (Figure 3(e)). This finding thus challenged the traditional view of the monophyly of African colobines. An ancient hybridization between Colobus male and Procolobus/Piliocolobus females had been proposed by them to explain their new finding. However, a most recent study of Wang et al. [31] supported the traditional view of the monophyly of the African colobines based on 44 nuclear non-coding genes and the whole mt genome (Figure 3(d) and (g)).

\section{Phylogeny of Asian Presbytina}

Compared with African colobinae, Asian Presbytina has more diverse members and wider geographic distribution $[1,12]$. The classification of Asian genera varies from 3 to 9 genera based on previous studies. Groves [32] and Grzimek [33] classified Asian colobines into three genera: Presbytis, Pygathrix, and Nasalis; Elliot [34] divided them into 4 genera: Pygathrix, Rhinopithecus, Nasalis, and Simias. Macdonald [35] also recognized 4 genera, but referred as Presbytis, Semnopithecus, Pygathrix, and Nasalis. In comparison, 

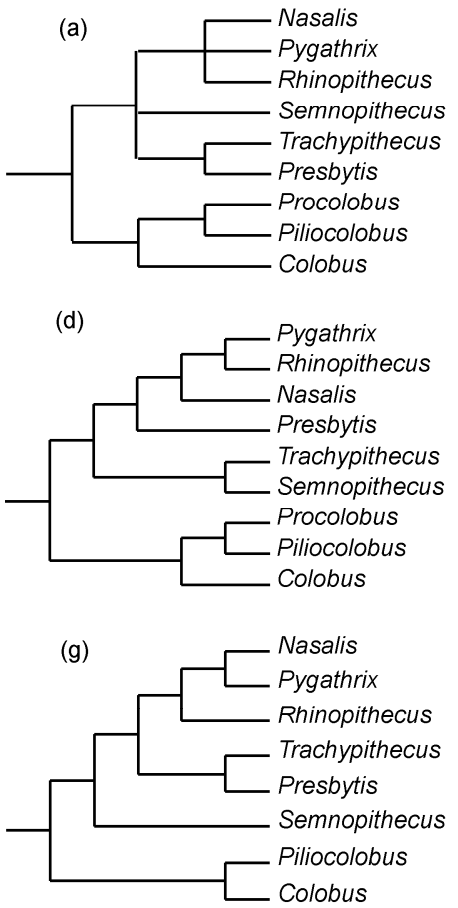
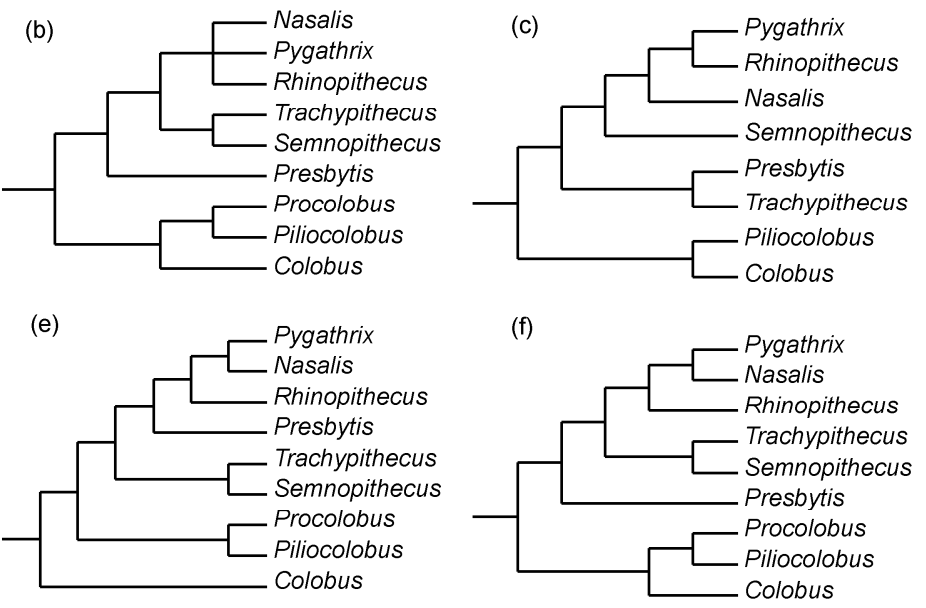

Figure 3 Hypotheses of phylogenetic relationships among Colobine genera. Trees were reconstructed based on (a) 12 protein-coding mt genes (10 kb) [17]; (b) fragment of X-chromosome (4.3 kb) [26] and 54 nuclear genes (35 kb) [18]; (c) complete cytb gene (1.8 kb) [30] and $7 \mathrm{mt} \mathrm{genes} \mathrm{(6.1} \mathrm{kb)} \mathrm{[29];} \mathrm{(d)} \mathrm{15} \mathrm{mt}$ genes and 43 nuclear genes (42 kb) [25], 44 nuclear non-coding genes (23 kb) [31]; (e) 83 mobile elements [19]; (f) nuclear genes (13 kb) [19]; (g) complete $\mathrm{mt}$ genomes $(16.5 \mathrm{~kb})$ [31].

Napier and Napier [36], Simpson [37], and Ellerman et al. [38] grouped the Asian colobines into five genera: Presbytis, Pygathrix, Rhinopithecus, Nasalis, and Simias, while Hershkovitz [39] and Nowak [40] proposed seven genera: Presbytis, Semnopithecus, Trachypithecus, Pygathrix, Rhinopithecus, Nasalis, and Simias. Hill [41-43] classified them into 9 genera: Presbytis, Semnopithecus, Trachypithecus, Pygathrix, Rhinopithecus, Nasalis, Simias, Kasi and Prebyticus. In recent years, there was a consensus that the Asian colobines were referred as langurs and comprised of 7 genera, i.e., Semnopithecus, Trachypithecus, Presbytis, Pygathrix, Rhinopithecus, Nasalis and Simias [1,12,14, 44,45]. In addition, these 7 genera were clustered into 2 groups, i.e., the odd-nosed monkey group (including $P y$ gathrix, Rhinopithecus, Nasalis and Simias) and the langur group (including Presbytis, Trachypithecus and Semnopithecus) [46-48].

Asian colobines represent a typical example of an evolutionary radiation with rapid diversification events that date back to Middle Miocene about 10-15 Ma [11,12]. Therefore, phylogenetic relationships within Asian colobines, including those among genera and some species had been disputed hotly in previous studies and were not well established yet [1,17-19,25,26,29-31,49-59].

\subsection{Intergeneric relationships within Asian Presbytina}

(i) Phylogeny of the odd-nosed monkey group. Though the monophyly of the odd-nosed monkey group has been unambiguously established from previous studies of both morphology and geographical distribution $[1,11,12,14,60]$ and confirmed by genetic data [17-19,26,30,31,52], there had long been controversy over the relationships among the genera within this group. It was especially the case that among Pygathrix, Rhinopithecus and Nasalis (Figure 3) [17-19,26,30,31,48].

Based on the previous morphological studies, Grove [46] and Delson [61] favored the association of Pygathrix and Rhinopithecus to the exclusion of Nasalis and this was congruent with molecular evidences based on the analyses of mitochondrial (mt) ND3-ND4 (2.2 kb), 12SrRNA (387 bp) genes by Wang et al. [49], and Li et al. [51], whereas Jablonski et al. [47,48,55] grouped Nasalis with Pygathrix to the exclusion of Rhinopithecus by combining fossils and 455 characters of morphological data. Zhang et al. [50] analyzed mt cytb gene fragment (424 bp) and support the sister-grouping of Nasalis and Rhinopithecus to the exclusion of Pygathrix. More recently, further efforts had been undertaken to obtain phylogenetic relationships using large datasets from $\mathrm{mt}$ genomes and nuclear genes. In the studies of Chatterjee et al. [29] (6.1 kb), Fabre et al. [25] (42 kb) and Meyer et al. [30] (1.8 kb), as well as Wang et al. [31] (23 $\mathrm{kb})$, all of which were conducted based on $\mathrm{mt}$ or nuclear sequence data, a sister-taxon association between Pygathrix and Rhinopithecus were consistently indicated (Figure 3(c) and (d)), whereas the studies of Roos et al. [19] and Wang 
et al. [31] supported a close association of Pygathrix with Nasalis to the exclusion of Rhinopithecus based on both 83 mobile elements (Figure 1(e)) and nuclear genes $(13 \mathrm{~kb})$ (Figure 3(f)) as well as the whole $\mathrm{mt}$ genomes $(16.5 \mathrm{~kb})$ (Figure 3(g)). Furthermore, Sterner et al. [17], Ting et al. [26] and Perelman et al. [18] also attempted to resolve the relationships among Pygathrix, Rhinopithecus, and Nasalis within the odd-nosed monkeys based on mt protein-coding genes (10 kb) (Figure 3(a)), X-chromosome (4.3 kb), and nuclear genes (35 kb) (Figure 3(b)), respectively, but the three genera formed a polytomy.

In comparison, when it came to the phylogenetic position of Simias in the odd-nosed monkey group, the debate on its systematic placement appeared remarkably subdued because all previous morphological and molecular analyses supported it as the sister-taxon (and possible subgenus) to Nasalis $[19,61,62]$, with the exception of a recent study of 7 mitochondrial $(\mathrm{mt})$ gene fragments $(6.1 \mathrm{~kb})$ from Chatterjee et al., [29] in which Simias had a closer relationship with Pygathrix/Rhinopithecus than Nasalis.

(ii) Phylogeny of the langur group. Another area being in hot dispute comes from the relationships between the langur genera and the odd-nosed monkey group. In fact, there has long been debate about the determination of three genera within the langur monkey group in earlier studies. Semnopithecus, and Trachypithecus had been ever grouped into Presbytis as one genus [46,63-66]. In comparison, more evidence separated Trachypithecus from Presbytis, including those from Oate et al. [67] and Brandon-Jones et al. [14] based on ecological and morphological data, as well as Md-Zain etc. based on $\mathrm{mt} N D 3, N D 4 L, N D 4$ (2.3 kb) [68] and COII (850 bp) [69] genes. Hill [43] and Hooijer [70] subdivide the genus Presbytis into Semnopithecus and Trachypithecus subgenus. In addition, Trachypithecus had also been formerly considered as a subgenus of Semnopithecus $[16,27,71,72]$.

Recent studies provided contradicting relationships between these three langur genera and the odd-nosed monkey group (Figure 3). Growing studies are supporting the nonmonophyly of the langur monkey group.

Sterner et al. [17] suggested a sister-group between Presbytis and Trachypithecus within the langur group, but failed to resolve the relationships among Presbytis/ Trachypithecus, Semnopithecus, and the odd-nosed monkey group based on $12 \mathrm{mt}$ protein-coding genes $(10 \mathrm{~kb})$ of 6 Asian colobine genera (Figure 3(a)). Ting et al. [26] claimed that Presbytis diverged earliest, followed by the split between Trachypithecus/Semnopithecus and the odd-nosed monkey group within the Asian colobines by examining a fragment of the X-chromosome ( $4.3 \mathrm{~kb})$ (Figure 3(b)). The results were congruent with the study by Perelman et al. [18] including $\sim 35 \mathrm{~kb}$ genome sequences from 54 nuclear genes of 186 primates. In contrast, both Chatterjee et al. [29] and Meyer et al. [30] favored the earliest divergence of Presbytis/Trachypithecus within Asian colobi- nae, and the close relatedness of Semnopithecus and the odd-nosed monkey group based on the analyses of $7 \mathrm{mt}$ genes $(6.1 \mathrm{~kb})$ and a fragment of $\mathrm{mt}$ genes $(1.8 \mathrm{~kb})$ (Figure 3(c)), but they lacked significant supports. Fabre et al. [25] analyzing combined $\mathrm{mt}$ and nuclear genes $(42 \mathrm{~kb})$, and Wang et al. [31] analyzing 44 nuclear non-coding genes (23 $\mathrm{kb}$ ), both found support for close relationships between Trachypithecus and Semnopithecus, and between Presbytis and the odd-nosed monkeys (Figure 3(d)). These same relationships were also confirmed by Roos et al. [19], who performed an analysis of 83 mobile elements (Figure 3(e)). Moreover, they also supported the former Semnopithecus/ Trachypithecus clade, but suggested Presbytis as sister to the other Asian colobines based on nuclear genome data analyses (13 kb) (Figure 3(f)). However, by analyzing the whole $\mathrm{mt}$ genome $(16.5 \mathrm{~kb})$, Wang et al. [31] proposed that Semnopithecus diverged earliest, followed by the split between Trachypithecus/Presbytis and the odd-nosed monkey group within the Asian colobines (Figure 3(g)).

The results from the above studies demonstrated that the relationships among langur monkey group and odd-nosed monkey group remain unresolved, although hybridization had been raised for a most likely explanation for some of these incongruent relationships $[19,73]$.

\subsection{Interspecies relationships within Asian Presbytina}

(i) Interspecific relationships in genus Rhinopithecus. The snub-nosed monkey genus Rhinopithecus is comprised of four distinct allopatric species [1,74]: $R$. brelichi (the gray snub-nosed monkey), $R$. bieti (the black snub-nosed monkey), $R$. roxellana (the golden snub-nosed monkey) and $R$. avunculus (the Tonkin snub-nosed monkey). Except for $R$. avunculus, which is distributed in low-altitude subtropical forests in northwestern Vietnam [75], the other three Rhinopithecus species are endemic to temperate areas of China and inhabit six isolated high-altitude mountainous regions [76].

The phylogenetic relationships among the four Rhinopithecus species had all along been focusing issues. As seen from Figure 4, contradictory conclusions had been reached under different analyses. Zhang and Ryder [77] and Wang et al. [31] supported the sister group of $R$. avunculus and $R$. bieti to the exclusion of $R$. roxellana by analyzing $\mathrm{mt} c y t b$ genes (253 bp) and 44 nuclear non-coding genes $(23 \mathrm{~kb})$, respectively (Figure 4(a)). Intriguingly, both Zhang and Ryder [50] and $\mathrm{Li}$ et al. [51] failed to resolve the phylogenetic relationships among $R$. bieti, $R$. roxellana and $R$. avunculus based on mt tRNA ${ }^{\mathrm{Thr}} /$ cytb genes (424 bp) (Figure 4b) and mt cytb genes (402 bp) (Figure 4(c)), respectively, but $R$. brelichi was supported to diverge earlier than the other three species in the latter study (Figure 4(c)). Interstingly, different from Zhang et al. [50], in which $\mathrm{mt}$ tRNA $^{\text {Thr }} /$ cytb genes were analyzed using MP and ML methods, Whittaker et al. [62] analyzed these two genes 

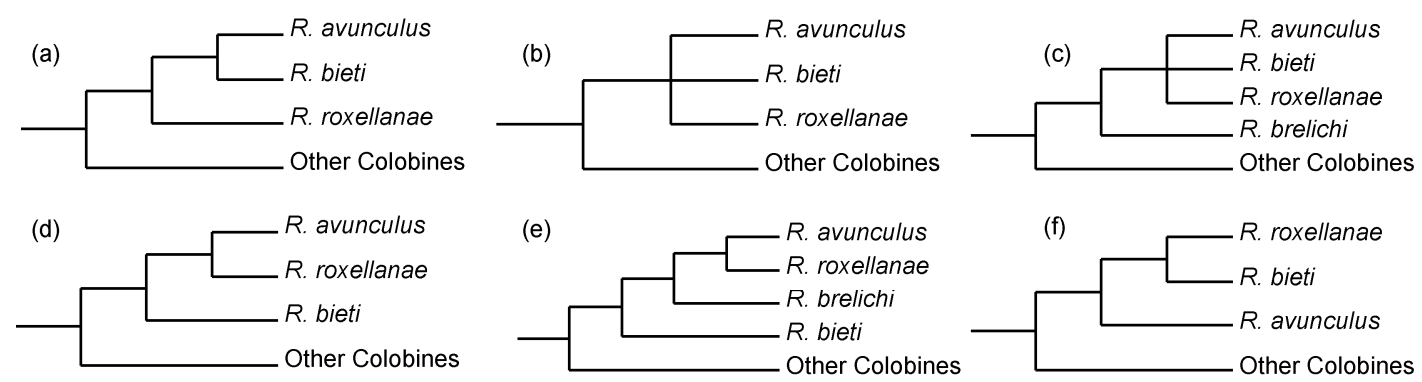

Figure 4 Hypotheses of phylogenetic relationships among four species of the genus Rhinopithecus. Trees were reconstructed based on (a) fragment of mt cytb gene (253 bp) [77], 44 nuclear non-coding genes (23 kb) [31]; (b) fragment of mt tRNA ${ }^{\text {Thr }} /$ cytb gene (424 bp) [50]; (c) fragment of mt cytb gene (402 bp), mt 12S rRNA gene (387 bp) [51]; (d) fragment of $\mathrm{mt} \mathrm{tRNA}^{\mathrm{Thr}} / \mathrm{cybt}$ gene (424 bp) [62]; (e) $15 \mathrm{mt}$ genes and 43 nuclear genes (42 kb) [25], $7 \mathrm{mt}$ genes (6,1 bp) [29]; (f) complete mt genomes (16.5 kb) [31].

using Bayesian method and supported the close relationship between $R$. roxellana and $R$. avunculus to the exclusion of $R$. bieti (Figure 4(d)). This relationship was also supported by Fabre et al. [25] and Chatterjee et al. [29], which utilized 15 $\mathrm{mt}$ and 43 nuclear genes (42 kb) (Figure 4(e)), as well as 7 $\mathrm{mt}$ fragment $(6.1 \mathrm{~kb})$ (Figure $4(\mathrm{e}))$, respectively. Interestingly, both Fabre et al. [25] and Chatterjee et al. [29] claimed the earliest divergent species among the genus Rhinopithecus group was $R$. bieti with significant support (Figure 4(e)), which was different from Li et al. [51] (Figure $4(\mathrm{c}))$. Recently, using the whole $\mathrm{mt}$ genome $(16.5 \mathrm{~kb})$, Wang et al. [31] supported the sister relationship between $R$. roxellana and $R$. bieti to the exclusion of $R$. avunculus (Figure 4(f)).

(ii) Interspecific relationships in genus Trachypithecus. Trachypithecus is the largest and most diverse genus of Asian Presbytina with a widest distribution, ranging from South India and Sri Lanka through mainland Southeast Asia to the Sundaland [52]. Within genus Trachypithecus, one species that had long been considered hard to determine phylogenetically is $T$. pileatus (the capped langur). Up to now, there were two conflicting hypotheses based upon previous analyses of mt $c y t b$ gene and two nuclear genes concerning the phylogenetic position of $T$. pileatus. Studies of partial $\mathrm{mt}$ genes clustered it with Semnopithecus $[29,52,78,79]$. However, nuclear gene based on Y chromosomal data and retroposon integrations analyses grouped it with Trachypithecus [52]. The remarkable discrepancy between $\mathrm{mt}$ and nuclear gene trees had led Osterholz et al. [52] and Karanth [80] to predict that T. pileatus might be the result of an ancient hybridization event between Semnopithecus and Trachypithecus. Additional information from $\mathrm{mt}$ and nuclear genomes should be added to resolve the enigmatic phylogenetic position of $T$. pileatus in the future studies.

Besides $T$. pileatus, the classifications and phylogenetic positions of $T$. johnii and $T$. vetulus had also been subjects of controversies in previous studies. In earlier studies, they were advised to be placed in their own genus Kasi due to their significant distinction from other species [42]. The subsequent analyses from the characters of cranial mor- phology, neonatal pelage color and sexually dichromatic pubic integument all classified them within Trachypithecus $[14,40,45]$, whereas the growing molecular data clustered them within Semnopithecus [18,29,31,50,52,62,79], leading to the proposal that they should be reclassified to be $S$. johnii and S. vetulus.

\section{Perspectives}

The phylogeny of colobine monkeys, which are characterized by rapid species radiations and short internal tree branches, has long been one of the most plaguing and challenging problems in species tree reconstruction [81-83]. Up to now, only the monophyly of the odd-nosed monkey group had been unambiguously accepted. Main controversies were concentrated on (1) the paraphyletic or monophyletic origin of African colobina, (2) the intergeneric relationships among the Asian colobines genus, (3) the interspecific relationships within the odd-nosed monkeys group, and (4) the precise placement of $T$. pileatus.

Therefore, finding valid genetic markers that offer sufficient variation to distinguish among the recently divergent Colobinae species posed a major challenge to advancing the understanding of Colobine phylogeny. Earlier investigations of Colobinae phylogeny mainly utilized analysis of portions of a single or a small number of mt genes [49-52]. Recently, more efforts had been made to obtain the phylogenetic tree using large dataset from mt genomes and multiple nuclear genes [17-19,25,26,29-31]. However, many relationships within Colobinae remained a polytomy, evidence from additional characters were thus necessary to resolve them in the future study.

As the increasing availability of genomic data of more species, phylogenetic analysis is entering a new era-Phylogenomics, which use genomic data to infer evolutionary relationships [84]. By performing phylogenomic study, we are most likely to reconstruct a reliable phylogenetic tree using much more characters than those in previous studies, including gene families, large insertion and deletion gene fragments, and gene rearrangement [85-87]. These charac- 
ters might be useful for distinguishing nodes resulting from rapid radiation episodes such as the Asian colobinae speciation events.

This work was supported by National Natural Science Foundation of China (U0836603) and Program for New Century Excellent Talents in University (NCET).

1 Groves C P. Primate Taxonomy. Washington: Smithsonian Institution Press, 2001

2 Fleagle J G. Old World Monkeys. In: Fleagle J G, ed. Primate Adaptation and Evolution. New York: Academic Press, 1998. 185-218

3 Oates J F, Davies A G, Delson E. What are the colobines? In: Davies A G, Oates J F, eds. Colobine Monkeys-Their Ecology, Behavior, and Evolution. Cambridge: Cambridge University Press, 1994. 1-10

4 Chivers D J, Hladik C M. Morphology of the gastrointestinal tract in primates: Comparisons with other mammals in relation to diet. $\mathrm{J}$ Morphol, 1980, 166: 337-386

5 Zhang J, Zhang Y P, Rosenberg H F. Adaptive evolution of a duplicated pancreatic ribonuclease gene in a leaf-eating monkey. Nat Genet, 2002, 30: 411-415

6 Zhang J. Parallel adaptive origins of digestive RNases in Asian and African leaf monkeys. Nat Genet, 2006, 38: 819-823

7 Yu L, Wang X Y, Jin W, et al. Adaptive evolution of digestive RNASE1 genes in leaf-eating monkeys revisited: New insights from ten additional colobines. Mol Biol Evol, 2010, 27: 121-131

8 Wang X Y, Li N Z, Yu L, et al. Duplication and functional diversification of pancreatic ribonuclease (RNASE1) gene. Chin Sci Bull, 2010, 55: 2-6

9 Wang X P, Jin W, Yu L, et al. Molecular evolution of stress-response gene Leptin in high-altitude Chinese snub-nosed monkeys (Rhiopithecus genus). Chin Sci Bull, 2010, 55: 4132-4135

10 Yu L, Wang X P, Ting N, et al. Mitogenomic analysis of Chinese snub-nosed monkeys: Evidence of positive selection in NADH dehydrogenase genes in high-altitude adaptation. Mitochondrion, 2011, 11: 497-503

11 Groves C P. A Theory of Human and Primate Evolution. Oxford: Oxford University Press, 1989

12 Davies A G, Oates J F. Colobine Monkeys: Their Ecology, Behavior, and Evolution. Cambridge: Cambridge University Press, 1994

13 Disotell T R. Primates: Phylogenetics. Encyclopedia of the Human Genome. London: Nature Publishing Group, 2003

14 Brandon-Jones D, Eudey A A, Geissmann T, et al. Asian Primate Classification. Int J Primatol, 2004, 25: 97-164

15 Stewart C B, Disotell T R. Primate evolution-in and out of Africa. Curr Biol, 1998, 8: R582-588

16 Delson E. Evolutionary history of the colobine monkeys in paleoenvironmental perspective. In: Davies A G, Oates J F, eds. Colobine Monkeys: Their Ecology, Behavior, and Evolution. Cambridge: Cambridge University Press, 1994. 11-44

17 Sterner K N, Raaum R L, Zhang Y P, et al. Mitochondrial data support an odd-nosed colobine clade. Mol Phylogenet Evol, 2006, 40: 1-7

18 Perelman P, Johnson W E, Roos C, et al. A molecular phylogeny of living primates. PLoS Genet, 2011, 7: e1001342

19 Roos C, Zinner D, Kubatko L S, et al. Nuclear versus mitochondrial DNA: Evidence for hybridization in colobine monkeys. BMC Evol Biol, 2011, 11: 77

20 Groves C P. The taxonomic diversity of the Colobinae of Africa. J Anthropol Sci, 2007, 85: 7-34

21 Grubb P, Butynski T M, Oates J F, et al. Assessment of the diversity of African primates. Int J Primatol, 2003, 24: 1301-1357

22 Kingston J D, Fine Jacobs B, Hill A, et al. Stratigraphy, age and environments of the late Miocene Mpesida Beds, Tugen Hills, Kenya. J Hum Evol, 2002, 42: 95-116

23 Groves C P. SUBFAMILY Colobinae. In: Wilson D E, Reeder D M, eds. Mammal Species of the World. 3rd ed. Baltimore: Johns Hopkins University Press, 2005. 167-178
24 Ting N. Mitochondrial relationships and divergence dates of the African colobines: Evidence of Miocene origins for the living colobus monkeys. J Hum Evol, 2008, 55: 312-325

25 Fabre P H, Rodrigues A, Douzery E J. Patterns of macroevolution among primates inferred from a supermatrix of mitochondrial and nuclear DNA. Mol Phylogenet Evol, 2009, 53: 808-825

26 Ting N, Tosi A J, Li Y, et al. Phylogenetic incongruence between nuclear and mitochondrial markers in the Asian colobines and the evolution of the langurs and leaf monkeys. Mol Phylogenet Evol, 2008, 46: 466-474

27 Strasser E, Delson E. Cladistic analysis of cercopithecid relationships. J Hum Evol, 1987, 16: 81-99

28 Grubb P, Butynski T M, Oates J F, et al. Assessment of the diversity of african primates. Int J Primatol, 2003, 24: 1301-1357

29 Chatterjee H J, Ho S Y, Barnes I, et al. Estimating the phylogeny and divergence times of primates using a supermatrix approach. BMC Evol Biol, 2009, 9: 259

30 Meyer D, Rinaldi I D, Ramlee H, et al. Mitochondrial phylogeny of leaf monkeys (genus Presbytis, Eschscholtz, 1821) with implications for taxonomy and conservation. Mol Phylogenet Evol, 2011, 59: 311-319

31 Wang X P, Yu L, Roos C, et al. Phylogenetic relationships among the Colobine monkeys revisited: New insight from analyses of complete $\mathrm{mt}$ genomes and 44 nuclear non-coding markers. PLoS One, 2012, 7 : e36274

32 Groves C P. The forgotten leaf-eaters and the phylogeny of Colobinae. In: Napier J R, Napier P H, eds. Old World Monkeys. New York: Academic Press, 1970. 629-647

33 Grzimek B. Grzimek's Encyclopedia of Mammals. New York: McGraw-Hill, 1990

34 Elliot D G. A Review of the Primates. New York: American Museum of Natural History, 1913

35 Macdonald D. The Encyclopedia of Mammals. New York: Facts on File Publication, 1984. 398-411

36 Napier J R, Napier P H. A Handbook of Living Primates. London: Academic Press, 1967

37 Simpson G G. The principles of classification and a classification of mammals. Bull Amer Mus Nat Hist, 1945, 85: 1-350

38 Ellerman J R, Morrison-Scott T C S. Checklist of Palaearctic and Indian mammals. London: British Musseum (Natural History), 1951. 1758-1946

39 Hershkovitz P. Living New World Primates (Platyrrhini), with an Introduction to Primates. Chicago: University of Chicago Press, 1977

40 Nowak R M, Walker S. Mammals of the World. Baltimore \& London: The Johns Hopkins University Press, 1991

41 Hill W C O. Primates: Comparative Anatomy and Taxonomy. Edinburgh: Edinburgh University Press, 1970

42 Hill W C O. Evolutionary Biology of the Primates. London: Academic Press, 1972

43 Hill W C O. A monograph on the purpled-faced leaf-monkeys (Pithecus vetulus). Ceylon J Sci, 1934, 9: 23-88

44 Groves C P. Cercopithecus and company: A primate radiation. Science, 1989, 244: 860-861

45 Eudey A A. Asian primate conservation-The species and the IUCN/ SSC primate specialist network. Primate Conservation, 1997, 17: $101-110$

46 Groves C P. The forgotten leaf-eaters and the phylogeny of Colobinae. In: Napier J R, Napier P H, eds. Old World Monkeys. New York: Academic Press, 1970. 555-586

47 Jablonski N G. The evolution of the doucs and snub-nosed monkeys and the question of the phyletic unity of the odd-nosed colobines. In: Jablonski N G, ed. The Natural History of the Doucs and Snub-Nosed Monkeys. Singapore: World Scientific Press, 1998. 13-52

48 Jablonski N G, Peng Y Z. The phylogenetic relationships and classification of the doucs and snub-nosed langurs of China and Vietnam. Folia Primatol, 1993, 60: 36-55

49 Wang W, Forstner M R J, Zhang Y P, et al. A phylogeny of Chinese leaf monkeys using mitochondrial ND3-ND4 gene sequences. Int J Primatol, 1997, 18: 305-320 
50 Zhang Y P, Ryder O A. Mitochondrial cytochrome $b$ gene sequences of Old World monkeys: With special reference on evolution of Asian colobines. Primates, 1998, 39: 39-49

51 Li M, Wei F, Huang C, et al. Phylogeny of snub-nosed monkeys inferred from Mitochondrial DNA, Cytochrome B, and 12S rRNA sequences. Int J Primatol, 2004, 25: 861-873

52 Osterholz M, Walter L, Roos C. Phylogenetic position of the langur genera Semnopithecus and Trachypithecus among Asian colobines, and genus affiliations of their species groups. BMC Evol Biol, 2008, 8: 58

53 Bigoni F, Houck M, Ryder O, et al. Chromosome painting shows that Pygathrix nemaeus has the most basal karyotype among Asian colobinae. Int J Primatol, 2004, 25: 679-688

54 Bigoni F, Stanyon R, Wimmer R, et al. Chromosome painting shows that the proboscis monkey (Nasalis larvatus) has a derived karyotype and is phylogenetically nested within Asian colobines. Am J Primatol, 2003, 60: 85-93

55 Jablonski N G. Quaternary environments and the evolution of primates in East Asia, with notes on two new specimens of fossil Cercopithecidae from China. Folia Primatol, 1993, 60: 118-132

56 Napier J R, Napier P H. Old World Monkeys. New York: Academic Press, 1970

57 Pan R. Dental variation among Asian colobines, with specific reference to the macaques on the same continent. Zool Res, 2007, 28: 569-579

58 Peng Y, Pan R, Ye Z, et al. Comparative study on cranioface and brain case in Asian colobines (in Chinese). Acta Anthropol Sin, 1991, 10: 346-356

59 Szalay F S, Delson E. Evolutionary History of the Primates. New York: Academic Press, 1979

60 Weitzel V, Yang C M, Groves C P. A catalogue of primate in the Singapore Zoological Reference Collection. Raffles Bull of Zool, 1988, 36: 1-166

61 Delson E. Evolutionary history of the Cercopithecidae. Contrib Primatol, 1975, 5: 167-217

62 Whittaker D J, Ting N, Melnick D J. Molecular phylogenetic affinities of the simakobu monkey (Simias concolor). Mol Phylogenet Evol, 2006, 39: 887-892

63 Li Z Y. Preliminary investigation of the habitats of Presbytis francoisi and Presbytis leucocephalus, with notes on the activity pattern of Presbytis leucocephalus. Folia Primatol (Basel), 1993, 60: 83-93

64 Peng Y Z, Ye Z Z, Pan R L. The classification and phylogeny of snub-nosed monkeys based on gross morphological characters. Zool Res, 1988, 9: 239-247

65 Pocock R I. The langurs, or leaf monkeys, of British India. Part II. J Bombay Nat Hist Soc 1928, 32: 660-677

66 Wolfheim J H. Primates of the World. Seattle: University of Washington Press, 1983

67 Oates J F, Davies A G, Delson E. The diversity of living colobines. In: Davies A G, Oates J F, eds. Colobine Monkeys: Their Ecology, Behavior, and Evolution. Cambridge: Cambridge University Press, 1994. 45-74

68 Md-Zain B M, Morales J C, Hasan M N, et al. Is Presbytis a distinct monophyletic genus: Inferences from mitochondrial DNA sequences. Asian Primates J, 2008, 1: 26-36

69 Md-Zain B M, Mohamad M, Ernie-Muneerah M A, et al. Phylogenetic relationships of Malaysian monkeys, Cercopithecidae, based on mitochondrial cytochrome $c$ sequences. Genet Mol Res, 2010, 9:
1987-1996

70 Hooijer D A. Quaternary Langurs and Macaques from the Malay archipelago. Zool Verhandelingen, 1962, 55: 1-64

71 Brandon-Jones D. Colobus and leaf monkeys. In: Macdonald D, ed. The Encyclopaedia of Mammals. London: Allen and Unwin, 1984. $398-410$

72 Brandon-Jones D. The Asian Colobinae (Mammalia: Cercopithecidae) as indicators of Quaternary climatic change. Biol J Linn Soc, 1996, 59: $327-350$

73 Karanth K P. Molecular systematics and conservation of the langurs and leaf monkeys of South Asia. J Genet, 2010, 89: 393-399

74 Jablonski N G, Peng Y Z. The phylogenetic relationships and classification of the doucs and snub-nosed langurs of China and Vietnam. Folia Primatol (Basel), 1993, 60: 36-55

75 Boonratana R, Le X C. Preliminary Observations of the Ecology and Behavior of the Tonkin Snub-nosed Monkey (Rhinopithecus [Presbytiscus] avunculus) in Northern Vietnam. In: Jablonski N G, ed. The Natural History of the Doucs and Snub-nosed Monkeys. Singapore: World Scientific Publishing, 1998

76 Kirkpatrick R C. Ecology and behavior in snub-nosed and douc langurs. In: Jablonski N G, ed. The Natural History of the Doucs and Snub-nosed Monkeys. Singapore: World Scientific Press, 1998. 155-190

77 Zhang Y, Ryder O A. Mitochondrial DNA sequence evolution and conservation relevance of snub-nosed langurs. Acta Genet Sin, 1997, 24: $116-121$

78 Geissmann T, Groves C P, Roos C. The Tenasserim Lutung, Trachypithecus barbei (Blyth, 1847) (Primates: Cercopithecidae): Description, of a live specimen, and a reassessment of phylogenetic affinities, taxonomic history, and distribution. Contrib Zool, 2004, 73: 271-282

79 Karanth K P, Singh L, Collura R V, et al. Molecular phylogeny and biogeography of langurs and leaf monkeys of South Asia (Primates: Colobinae). Mol Phylogenet Evol, 2008, 46: 683-694

80 Karanth K P. Primate numts and reticulate evolution of capped and golden leaf monkeys (Primates: Colobinae). J Biosci, 2008, 33: 761770

81 Rokas A, Carroll S B. Bushes in the tree of life. PLoS Biol, 2006, 4: 1899-1904

82 Philippe H, Chenuil A, Adoutte A. Can the Cambrian explosion be inferred through molecular phylogeny? Development, 1994, 120: S15-S25

83 Saitou N, Nei M. The number of nucleotides required to determine the branching order of three species, with special reference to the human-chimpanzee-gorilla divergence. J Mol Evol, 1986, 24: 189204

84 Yu L, Zhang Y P. Phylogenomics: An attractive avenue to reconstruct "tree of life" (in Chinese). Hereditas, 2006, 28: 1445-1450

85 Meslin C, Brimau F, Nagnan-Le Meillour P, et al. The evolutionary history of the SAL1 gene family in eutherian mammals. BMC Evol Biol, 2011, 11: 148

86 Wu Y C, Rasmussen M D, Kellis M. Evolution at the subgene level: Domain rearrangements in the Drosophila phylogeny. Mol Biol Evol, 2011, 29: 689-705

87 Yu L, Luan P T, Jin W, et al. Phylogenetic utility of nuclear introns in interfamilial relationships of Caniformia (order Carnivora). Syst Biol, 2011, 60: 175-187

Open Access This article is distributed under the terms of the Creative Commons Attribution License which permits any use, distribution, and reproduction in any medium, provided the original author(s) and source are credited. 